\title{
Historiografia e ensino de história: algumas reflexões sobre o ensino fundamental.
}

Airton de Moraes ${ }^{l}$

Resumo

Este artigo tem como objetivo apresentar uma análise dos resultados do teste piloto de uma pesquisa realizada junto ao programa de mestrado em Educação da Universidade Estadual de Londrina que pretende mapear a influência das vertentes historiográficas no dia-a-dia do professor de História que atua no Ensino Fundamental. Na referida etapa da pesquisa buscamos testar a validade do instrumento de coleta de dados. Para tal, trabalhamos com duas turmas de alunos da $5^{\mathrm{a}}$ série sendo uma da rede pública, outra da rede particular de ensino. Estes alunos responderam um questionário com duas partes. Na primeira, priorizamos levantar dados sobre o acesso dos mesmos a internet, filmes e a literatura. $\mathrm{Na}$ etapa final, foram aplicadas cinco questões visando levantar informações referentes aos conhecimentos prévios ou tácitos substantivos sobre sociedade e trabalho na Idade Média.

Palavras-chave: Ensino de História, Metodologia de Ensino, Historiografia.

Este artigo tem como propósito principal apresentar as análises parciais da pesquisa realizada junto ao programa de mestrado em Educação da Universidade Estadual de Londrina, Paraná. ${ }^{2}$ A gênese deste trabalho, que tem como foco principal mapear se as novas abordagens historiográficas estão presentes na sala de aula e quais os possíveis efeitos destas na formação histórica dos alunos do Ensino Fundamental, surgiu durante a realização do estágio obrigatório do curso de graduação em História.

Na referida parte do curso, pudemos constatar que várias das discussões acerca das novas abordagens historiográficas, realizadas durante a graduação

1 Graduado em História e mestrando em Educação pela Universidade Estadual de Londrina.

2 Este trabalho, orientado pela professora doutora Marlene Rosa Cainelli, tem como tínulo "provisório" "As influências das abordagens historiográficas no ensino fundamental". 
em História, não estavam presentes nas salas de aula que observamos durante o estágio. Ou seja, alguns procedimentos presenciados contradiziam as novas questões discutidas no âmbito universitário há quase 20 anos.

Outro fator que nos "incomodou" foi o grande desinteresse da "sala" pela disciplina, fato este confirmado pelo professor regente. Intrigados por esta constatação, ainda durante o referido estágio, realizamos uma rápida pesquisa oral com alguns alunos da $6^{\text {a }}$ série do Ensino Fundamental, visando identificar possíveis causas de tal comportamento. Apesar da pouca sistematização e informalidade da coleta de dados, algumas informações chamaram a atenção.

Em linhas gerais, a grande totalidade do grupo questionado não via aplicação cotidiana para tal disciplina. Em outras palavras, não sabiam para que servia 0 estudo da História. A constatação destes fatos contribuiu de forma decisiva para que, no momento ulterior ao término da graduação, elaborássemos uma pesquisa que abarcasse de forma consistente 0 referido tema.

Para desenvolver este artigo optamos por uma discussão que englobará três frentes: na primeira delas, destacaremos algumas discussões presentes na literatura sobre o sentido do ensino de História. Ainda nesta parte, buscaremos de forma pontual, discutir sobre a atuação do professor de História em sala de aula. E, finalizando este primeiro momento, faremos de forma sucinta um breve apontamento sobre algumas abordagens historiográficas. Na segunda parte, serão apresentados alguns autores que advogam a importância do teste piloto numa pesquisa científica. Ainda buscaremos relatar de forma pontual 0 trabalho desenvolvido por FERREIRA, et al. (2004) que serviu de base para a realização e análise do referido teste. Na parte final do artigo, apresentaremos as questões formuladas, bem como as respostas dos alunos quando questionados sobre "Trabalho e sociedade na Idade Média".

0 questionamento sobre a falta de sentido e utilidade do ensino de História apresentado pelos alunos da $6^{\mathrm{a}}$ série do Ensino Fundamental durante a breve pesquisa já relatada é um tema fulcral, que há muito vem gerando calorosas discussões seja no dia-a-dia do cidadão comum, bem como no campo acadêmico da História, Sociologia, Filosofia, entre outros saberes. Só para citar um exemplo clássico fora da academia, o historiador francês Marc BLOCH (2001, p. 41) relata-nos que seu filho fizera a seguinte pergunta nas décadas iniciais do século XX: "Papai, então me explica para que serve a história". 
Visando trazer subsídios para uma possível resposta, nos remeteremos a alguns recortes de textos produzidos ao longo da História. 0 primeiro autor com quem conversaremos é Immanuel Kant. Em linhas gerais, para este filósofo alemão que viveu no século XVIII, todas as realizações humanas e acontecimentos naturais são regidos por lei. A História se " [...] ocupa da narrativa dessas manifestações, por mais profundamente ocultas que possam estar as suas causas, permitem todavia esperar que, com a observação [...] possa descobrir aí um curso regular [...]” (TERRA, 1986). Podemos observar neste pequeno fragmento de texto que existe uma função pedagógica, ou seja, através do estudo detalhado da Clio, encontraríamos o fio condutor presente no tempo e no espaço.

Outro teórico que utilizaremos em nosso texto é Roger George COLLINGWOOD, historiador inglês nascido no século XIX. Apesar de toda a crítica feita à sua teoria do conhecimento histórico, principalmente no que se refere a necessidade do pesquisador reconstruir o pensamento das pessoas envolvidas na trama, é pertinente destacar a importância que o autor releva para a História (HUGHES-WARRINGTON, 2002; GARDINER, 1984). Para ele, os estudos históricos possibilitam ao homem se auto-conhecer. Ou seja, "[...] como ninguém sabe o que pode fazer antes de tentar, a única indicação para aquilo que o homem pode fazer é aquilo que já fez. 0 valor da história está então em ensinar-mos o que o homem tem feito e, deste modo, o que o homem é" (COLLINGWOOD, [196-?], p. 22).

Retomando a pergunta feita pelo menino ao pai historiador, e diante dos exemplos expostos, ensinar História seria pertinente, ou apenas se limitaria a agradáveis momento em que levaríamos nossos alunos a uma catarse coletiva? Para todos esses dilemas faremos nossa as palavras de BLOCH (2001, p. 65) "[...] a incompreensão do presente nasce fatalmente da ignorância do passado". Se tomarmos tal citação como "verdade", o estudo histórico é importante para que o novo homem que está sendo formado possa compreender a sua base ou raiz que foi construída durante os séculos num processo permeado por constantes rupturas e permanências.

Diante deste axioma, BRANDÃO (1989) assevera que o processo educativo é a forma pela qual se dá a transmissão da cultura sistematizada historicamente. Ou seja, é através da educação, seja ela de modo formal ou informal, que os 
indivíduos adultos visam formar cidadãos que dêem continuidade ao processo de inserção social iniciado pelos seus antecessores. Em síntese, o aprendizado tem como prioridade proporcionar aos seres humanos o conhecimento dos costumes, crenças e, acima de tudo, do próprio ser. Esses requisitos são imprescindiveis para o processo de socialização que, segundo SAVATER (1998), é condição sine qua non para nos tornarmos humanos, ou seja, nascemos para sermos humanos e o contato com os nossos semelhantes nos faz "verdadeiramente" humanos.

Como podemos observar, o conhecimento histórico, juntamente com os demais saberes, é de suma importância para a constituição e continuidade de uma sociedade. Mas o que dizer do fato que nossos alunos e a sociedade de forma geral não dão importância para seu estudo? Quais caminhos poderiam ser traçados pelo docente para que seu público percebesse a relevância do estudo da História?

Um primeiro aspecto a ser abordado, que poderia contribuir de forma decisiva para a valorização dos estudos históricos, está ligado à formação do profissional que atuará nas salas de aula como professor de História. Para muitas instituições de ensino, bem como pais e alunos, ensinar história é algo fácil e muito simples (ROCHA, 1999). Amiúde, são deslocados para essa disciplina profissionais formados em outras áreas tidas como afins. Em nosso entendimento, o primeiro passo, para que o professor possa conseguir mostrar para que serve a História, é uma boa formação acadêmica. Isto é, ensinar História implica em ter um cabedal teórico-metodológico pertinente ao seu papel. Parafraseando ROCHA (1999), sem uma boa qualificação não haverá ensino de qualidade.

Visando reforçar tal argumento, utilizaremos uma citação de HOBSBAWN (1998, p. 17), na qual o autor inglês mostra que a função do historiador demanda uma formação de boa qualidade bem como uma ética profissional, pois assim como o físico nuclear " [...] nossos estudos podem se converter em fábricas de bombas, como os seminários nos quais o IRA aprendeu a transformar fertilizante químico em explosivo [...]". Trazendo para o magistério, são incomensuráveis os malefícios que um ensino de História pode trazer aos alunos quando por motivos de incompetência ou de forma intencional 0 responsável pela disciplina não detém uma leitura crítica e apurada do passado. 
Diante disto, um dos vários pilares, que sustenta um ensino de boa qualidade, é a busca constante de uma excelência na formação. Em outras palavras, para que possa levar o aluno a compreender a função social da História desde tenra idade, o profissional deve ter durante o período de sua formação acadêmica, uma boa qualificação.

Porém, em relação à procura desta excelência, Ciro Flamarion Santana Cardoso, no início da década de 80 do último século, visualizava e destacava alguns equívocos presentes nas práticas pedagógicas durante a formação do professor de História. Para CARDOSO (1984, p. 81-82) “[...] muitos professores, por sua preparação ou interesse, se concentram em 'expor' conhecimentos [...] como esperar, então, que de repente [0 graduando] sem problemas possa ser arrancado à aprendizagem livresca e repetitiva que conheceu desde os sete anos de idade?".

Neste mesmo sentido, VILLALTA (1992-3, p. 229) faz duras críticas ao modelo educacional brasileiro relacionada à formação do professor de História. Segundo ele:

os departamentos de História, via de regra, não estão preocupados com a formação de professores de História. [Diante disso] não estão organizados de forma que essa perspectiva esteja sempre presente no dia-a-dia dos seus mestres. Nos cursos de História estabelecem uma dicotomia entre as disciplinas de conteúdo [...] e as de 'instrumentação tecnológica'

A idéia capital a ser destacada nesta última citação é que não há uma interação entre as matérias pedagógicas e o Ensino de História. Urge então, a necessidade de um maior entrosamento entre os profissionais dos dois Departamentos: História e Educação, visando traçar estratégias que tragam benefícios à formação do aluno. Há também no artigo acima citado críticas feitas pelo historiador aos Departamentos de Educação. Para este, não há uma diferenciação dos cursos e assim, o currículo pedagógico é na maioria das vezes o mesmo para todas as licenciaturas.

Outra admoestação feita por VILLALTA (1992-3) tange à questão da prática pedagógica dos alunos. Para ele, além do estágio ter seu início logo nas primeiras séries do curso de graduação, o professor deveria estar sempre por 
perto para intervir quando necessário. Esse processo de acompanhamento conjuntamente com as discussões teóricas presentes nas aulas contribuiriam para que os alunos fossem mais capacitados para sua futura profissão.

Estes duros apontamentos feitos por estes profissionais há décadas podem trazer elementos para repensarmos a formação de professores de História. Ou seja, é principalmente nas academias que se dá o processo de "lapidação" da "matéria-prima" que servirá de base para a formação e condução intelectual de nossos aprendizes sociais no início da vida escolar.

A questão da formação do professor não se restringe aos anos da licenciatura. Sem entrar a fundo no mérito propriamente dito, sabemos que somente a formação inicial não é suficiente para que o profissional dê conta de atender as novas demandas que surgem a cada dia. 0 professor deve estar pronto para constantemente pensar sobre seu fazer, mas “[...] a reflexão [será] mais fecunda se também for cultivada com leituras, formações e saberes acadêmicos [...]" (PERRENOUD, 2002, p. 52). Diante disso, devemos enfatizar a necessidade de uma formação continuada, seja na forma de cursos de pósgraduação ou ainda participação de eventos, seminários e congressos.

0 dinamismo e provisoriedade do processo histórico, são pontos que, quando abordados de forma devida, contribuirão para a valorização do estudo histórico. Porém, precisa-se elaborar estratégias para que o aluno possa constatar que o processo histórico é algo construído por todos os agentes sociais, independente de sua classe, casta ou credo religioso. A História não é um produto pronto, acabado e sim um processo dinâmico que envolve inúmeros fatores do qual todos participamos.

Corroborando nossa assertiva, CABRINI (2000) afirma que o professor tem que ensinar seus "discípulos" a pensar historicamente. Por exemplo: mostrar as questões referentes a rupturas e permanências; situá-los na questão conjuntural e estrutural - história de curta, média e longa duração. Para 0 aluno aprender a ter esse raciocínio histórico, o professor precisar dispor de várias estratégias e abordagens desafiadoras.

Segundo a autora, uma dessas possibilidades é o trabalho com documentos em sala de aula, pois durante o processo da leitura crítica dos mesmos, o aluno, devidamente acompanhado do professor que teve uma formação teórica sólida, perceberá que o documento em questão foi construído 
num determinado tempo histórico, e sua interpretação depende do local, época e público que 0 analisará.

Seguindo esta linha de raciocínio, o historiador José Carlos REIS (2002, p.11) traz em um de seus textos algumas afirmações que poderão servir de subsídios para que os professores possam perceber, e levar para a sala de aula, que a História está em contínua construção.

Em cada presente, o que se tem é uma visão parcial, uma articulação original do passado e do futuro. A história é visada segundo perspectivas diversas, e, com 0 avanço do tempo, as proposições históricas mudam. Todo o historiador émarcado por seu lugar social, por sua 'data'e por sua pessoa. Vêem-se sempre aparecer obras novas sobre o mesmo assunto. À medida que o tempo passa, novas experiências são acrescentadas às precedentes, e novas esperas são desenhadas. 0 passado é assaltado por interrogações novas, que oferecem respostas diferentes das anteriores. Em cada presente há um esforço de compreensão: de autolocalização pela rearticulação de passado e futuro.

0 contato com apontamentos, como este relatado nas linhas anteriores, poderá contribuir para que o professor venha propor formas de trabalho visando desmistificar para os alunos, toda "áurea" que envolve o fazer histórico. Ou seja, mesmo correndo risco de anacronismo, ao citar um conceito elaborado historicamente para a Idade Média, enfatizamos que a construção histórica é feita por homens, mulheres e crianças pertencentes a "nobreza", "clero" e "servos". Ou ainda, segundo Jaime PINSKY e Carla B. PINSKY (2003, p.35), o aluno precisa ser provocado a compreender que o processo histórico é construído por "[...] gente como a gente".

Sendo assim, por exemplo, se faz necessário discutir entre os pares, e até com os alunos, quais os critérios utilizados pelos autores dos livros didáticos no momento da elaboração do material. Este trabalho tem como objetivo central mostrar aos seus alunos que os textos e recortes temáticos presentes no material didático não são dogmas, e sim uma seleção, fatos determinados por um conjunto de elementos presentes na sociedade. Numa leitura mais especializada poderia tentar identificar, juntamente com outros colegas, qual ou quais escolas históricas pertence a linha editorial. 
A questão teórica enfatizada no último parágrafo é muito relevante no ensino, uma vez que seja nas conduções das aulas pelo professor ou no processo de redação final dos manuais didáticos, sempre há uma linha teórica que conduz às ações. Sendo assim, mesmo sabedor do difícil fazer docente, devido a excessivo número de alunos ou horas trabalhadas, se faz necessário buscar e trazer novas discussões presentes nas academias para dentro da sala de aula do Ensino Fundamental e Médio.

Algumas pessoas podem questionar qual seria a utilidade do professor estudar as tendências históricas, uma vez que seu público e, conseqüentemente, o foco de ensino não estão ligados diretamente à teoria. Para responder a tal questionamento utilizaremos os argumentos de BURKE (2002, p. 35). 0 historiador inglês salienta que "[...] sem combinar a história com a teoria, é provável que não consigamos entender nem o passado nem o presente". Portanto, preconizamos aos professores o estudo das principais escolas históricas que exerceram influência em solo nacional.

Devido à especificidade deste artigo, será feita uma análise sucinta do tema. Convém enfatizar ainda que esta exposição, mais do que mostrar uma "evolução" na discussão historiográfica e, conseqüentemente, no Ensino de História, tem por objetivo apresentar abordagens que em diferentes períodos influenciaram e continuam influenciando o dia-a-dia do fazer docente no Ensino de História.

Iniciaremos nossa "conversa" com Auguste Comte - considerado fundador de uma corrente filosófica que influenciou a maneira de escrever a História. Em linhas gerais, para o Positivismo de Comte, toda sociedade passaria necessariamente por três fases ou estados, a saber: teleológico; metafísico; positivo ou científico (RIBEIRO JR, 1996). No último estado, o positivo, se buscava através da ciência uma verdade absoluta e universal e, para ser reconhecida como verdadeiro, necessariamente, deveria receber a chancela do Estado.

No início do século XIX na Alemanha e logo em seguida na Franca, tivemos um movimento conhecido como "Escola Metódica" que buscou no Positivismo alguns conceitos. Segundo REIS (2004), Leopold von Ranke, o fundador desta escola histórica, asseverava que a função do historiador era reunir dados organizando-os em um seqüência cronológica. Em linhas gerais, para Ranke seria possível a neutralidade histórica. Para tal, ao coligir os fatos, o historiador não poderia emitir juízo, pois os mesmos falam por si. 
0 corolário desta vertente no Ensino de História brasileiro foi a priorização do ensino factual, voltado para os eventos políticos. Ou seja, o ensino do "Político" passa então a ter grande importância, e para tal surge a necessidade de aprender nomes de heróis nacionais e datas comemorativas.

Quanto ao processo de ensino-aprendizagem centrado nesta abordagem, destaca-se a preocupação em levar o aluno a acumular um conjunto de dados. Porém, devido à falta da problematização, esta educação bancária, centrada na memorização mecânica de grandes episódios da vida nacional, pouco contribui para a formação de um senso crítico do aluno, uma vez que neste modelo de ensino de História, o aluno não se reconhece como agente deste processo. A história é feita por uma elite dominante retratada nos livros didáticos elaborados pela mesma.

Também no século XIX, tem início na Alemanha, um movimento de cunho materialista. Fazendo duras críticas ao método Hegeliano que predominava em diversas academias européias do período, Karl Marx enfatiza que, a revolução proletária seria responsável pela transformação do mundo. Portanto, invertendo a dialética Hegeliana, Marx introduziu uma nova concepção ao estudo da História da Humanidade. Nesta, o motor da história é a luta de classes. Portanto, o homem é 0 único responsável pelas transformações que ocorrem, isto é, eles fazem a história e não simplesmente, como defendia Hegel, são fantoches de um ser metafísico (REIS, 2004).

Segundo tal vertente filosófica, as contradições que paulatinamente suscitaram nos diferentes modos de produção, fizeram com que, através do processo dialético, ocorressem as mudanças na humanidade. Em outras palavras, o embate entre classes, tendo como pano de fundo o poder econômico, proporcionou a evolução. Embasado num conceito teleológico, tal ideologia advoga que os próximos estádios da humanidade seriam: a instalação de uma ditadura proletária e que se consubstanciaria no comunismo. Alguns historiadores fazem pesadas críticas ao marxismo dito ortodoxo. Para Philippe TÉTART (2000, p.115) nesta vertente historiográfica "[...] o acontecimento é abandonado [...] e o homem não existe enquanto indivíduo e sim enquanto classe social".

No Ensino de História no Brasil, percebe-se claramente a influência da vertente marxista. Um exemplo bem marcante desta corrente são os ciclos econômicos Pau-Brasil, Cana-de-açúcar, Ouro - ciclos que delimitaram as fases do nosso 
desenvolvimento. Para alguns críticos, a leitura tradicional marxista da história priorizaria o fator econômico, negligenciando fatores sócio-culturais, por exemplo. (COLLINGWOOD, [196-?]; REALE; ANTISERI, 1991).

Neste terceiro momento, destacaremos um movimento liderado por historiadores franceses que ficou conhecido como a Escola dos Annales. Surgida na França em 1929 e liderada por Lucien Fevbre e Marc Bloch, fizeram, para alguns estudiosos, uma "Revolução na historiografia" (BURKE,1997; DOSSE, 1998). Rompendo com uma história factual e política influenciada pelo positivismo, este grupo composto por uma equipe multidisciplinar, fez uma releitura da história, apresentando "Novas Abordagens", "Novos Problemas" e "Novos Objetos" (LE GOFF; NORA, 1979, 1988a, 1988b).

A partir deste contexto, os ditos excluídos - negros, mulheres, crianças ganham seu espaço na historiografia. Segundo TÉTART (2000, p. 109-10) os Annales desceram "[...] ao porão da História recusando o elitismo dos assuntos e a prioridade do acontecimento. A partir de então [...] a extensão da curiosidade do historiador não tem mais limites [...]". Portanto, podemos concluir embasados em alguns autores citados, que esta tendência historiográfica priorizou uma leitura sócio-cultural da História.

No Brasil, ainda é incipiente esta discussão em sala de aula, mas existe a preocupação de alguns autores que escrevem livros didáticos em apresentar esta nova concepção, permitindo assim ao aluno perceber que a História é um processo e, principalmente, que ele e os demais são agentes e não meros espectadores deste grande filme. Uma crítica à Escola dos Annales diz respeito à marginalização da história política, isto é, reabilitando os ditos "excluídos", adota-se uma leitura historiográfica "vista por baixo", esquecendo que as decisões, na quase totalidade das vezes, são tomadas em nível político (DOSSE, 1998; REMOND, 1998).

Esta crítica feita por alguns historiadores aos Annales tem que ser levada em consideração. Sendo assim, o professor em sala de aula, ao mostrar 0 processo histórico, deve proporcionar aos alunos subsídios para que os mesmos tenham consciência de que fazem parte de um todo constituído de indivíduos representados por instituições laicas, eclesiásticas e públicas, que se consubstanciam em uma nação. ${ }^{3}$

\footnotetext{
3 Esta exposição, como já salientamos, não visou fazer um tratado sobre o tema. Devido ao recorte e foco do texto, outras tendências ficaram de fora da rápida análise. Por exemplo, há um grupo de estudiosos ingleses e alemães que fizeram uma crítica a modelo marxista tradicional, apresentando assim, uma nova forma de ler o "mundo" com as lentes de Karl Marx (BARROS, 2004).
} 
Mais do que denotar uma evolução na discussão historiográfica e conseqüentemente no Ensino de História, tal abordagem teve por objetivo apresentar que tais correntes influenciaram e continuam influenciando o diaa-dia do fazer docente no Ensino de História. Não se está concluindo, por exemplo, que o grupo dos Annales é superior ao Positivismo, mas sim que suas abordagens vêm ao encontro das necessidades colocadas por suas épocas. Segundo REIS (2002), cada presente opta por um passado que mais lhe convém.

Porém, como salientamos no início desta discussão, o que importa para 0 professor de História não é ser um especialista sobre os assuntos teóricos mas sim conhecer de forma suficiente para entender que os mesmos influenciam na maneira de escrever e ensinar História. Ademais, é sempre interessante retomar as pertinentes palavras de um dos fundadores da Escola de Annales: "É bom, ao meu ver, é indispensável que 0 historiador possua ao menos um verniz de todas as principais técnicas [e teorias] de seu ofício [...]" (BLOCH, 2001, p. 81).

Dando continuidade à nossa conversa, procuraremos apresentar de forma sucinta a organização do trabalho que estamos desenvolvendo no Mestrado em Educação. Nossa pesquisa, como já informamos, visa analisar se as novas abordagens historiográficas então presentes no Ensino Fundamental, bem como a sua influência na aula de História. Optamos por trabalhar com duas turmas de $6^{\text {a }}$ série do Ensino Fundamental, escolhidas em dois estabelecimentos: uma da rede pública e outra da rede particular de ensino do município de Londrina.

Algumas questões foram levadas em consideração na escolha desse público. Primeiro, como foi relatado, já tivemos contato com esta série durante a realização do estágio obrigatório do curso de História. Também levou-se em consideração a fase educacional dos alunos, uma vez que o mesmo nessa etapa escolar já passou, a priori, pelo processo de adaptação inicial do terceiro ciclo do Ensino Fundamental. Finalizando, a escolha de duas instituições uma pública e outra privada foi no intuito de levantar subsídios para verificar se as questões sócio-econômicas influenciam na compreensão do ensino de História, ou seja, analisar se o significante - ensino de História - tem o mesmo significado para ambos.

Diante das características suscitadas pelo objeto a ser estudado, ou seja, devido à complexidade, amplitude e dinamismo do nosso recorte, optamos por 
fazer uma pesquisa qualitativa do tipo etnográfica. Tal modalidade de pesquisa surgiu no final do século XIX na tentativa de contrapor o modelo Positivista que imperava nas Academias. 0 enfoque do Positivismo, segundo os críticos, não era suficiente para analisar o homem holisticamente, isto é, o estabelecimento de leis gerais imutáveis não davam conta de responder a complexidade e o dinamismo do ser humano.

No que tange especificamente à pesquisa do tipo etnográfica, se faz necessário relatar que sua gênese se deu na antropologia, quando estudiosos se instalaram no interior de algumas tribos com o intuito de entender sua dinâmica (CHIZZOTTI, 1991; ANDRÉ, 1995).

Uma das características presentes nas pesquisas qualitativas que levounos a elegê-la como metodologia para esta pesquisa diz respeito à delimitação e formulação do problema. Ou seja, "[...] a identificaçã̃o do problema e sua delimitação pressupõe uma imersão do pesquisador na vida e no contexto, no passado e nas circunstâncias presentes que condicionam o problema" (CHIZZOTTI, 1991, p. 81). No nosso caso, presenciamos o dilema em sala de aula seja no questionamento dos alunos quanto à utilidade da História, seja na forma tradicional de atuar dos docentes.

Em relação à coleta de dados, optamos, devido a especificidade do trabalho, por utilizar a técnica da triangulação. Segundo TRIVIÑOS (1987, p. 138), devido à complexidade dos fenômenos sociais, essa técnica "[...] tem por objetivo básico abranger a máxima amplitude na descrição, explicaçã̃o e compreensão do foco em estudo". Sendo assim, visando coligir um maior número de dados, nos propusemos em utilizar: questionários com os alunos; entrevistas com professores e coordenadores; observação em sala de aula; análise do material didático.

0 questionário aplicado aos alunos bem como sua interpretação foi uma adaptação do modelo utilizado na pesquisa-ação realizado por FERREIRA, et al. (2004) com o título "0 conceito de renascimento: uma experiência com alunos de $8^{\circ}$ ano". Em suma, o grupo em questão buscou analisar a influência do ensino de História na mudança dos conhecilentos tácitos dos alunos, e para tal estudo, o tema escolhido pelas pesquisadoras portuguesas foi o Renascimento.

A pesquisa, que foi desenvolvida conjuntamente com alunos do $8^{\circ}$ ano de 
escolaridade, procurou identificar em três aulas (duas de noventa minutos e uma de quarenta e cinco minutos) as mudanças ocorridas na concepção dos alunos acerca do conceito de Renascimento. Elegeram, para a execução do projeto, turmas de diferentes meios socioculturais (urbano e rural) das quais, antes do início do conteúdo, foram construídas fichas das idéias tácitas ${ }^{4}$ dos alunos acerca do tema já mencionado. A idéia principal era que "[...] os alunos se exprimissem livremente sobre o conceito proposto, de forma a comunicarem as idéias já adquiridas na aprendizagem informal"(FERREIRA, et al., 2004, p. 149).

As respostas dos alunos, seja na primeira fase quanto na segunda, foram divididas em: conceitos alternativos subjetivos; conceitos alternativos do senso comum; conceitos históricos aproximados; conceitos históricos científicos. Com tal sistematização, foi possível averiguar as possíveis influências das aulas no processo de construção do conceito histórico em questão.

Em linhas gerais, as autoras, num primeiro instante, aplicaram um instrumento de coleta de dados. 0 objetivo era fazer um levantamento das idéias prévias dos alunos sobre o tema abordado. Após esta fase, foram constituídos grupos para discutirem sobre os conceitos apresentados pelos colegas. No momento seguinte, foi realizada uma avaliação oral visando identificar o conceito que cada discente tinha sobre o tema. Logo a seguir, os grupos voltaram a discutir sobre o Renascimento mas com o apoio de documentos históricos.

Após este momento, novamente foi aplicada uma outra avaliação oral, visando, assim como na primeira, partilhar conhecimento com a turma. No momento posterior, foram apresentados um conjunto de fontes pertinentes ao período histórico para os alunos analisarem. E, finalmente, os alunos preencheram novamente a ficha de idéias tácitas. Além do substancial aumento do vocabulário observado na turma, para as autoras do artigo houve uma mudança considerável quanto ao conceito sobre Idade Média, ou seja:

a experiência educativa permitiu-nos analisar a mudança conceptual operada nos alunos $[\ldots]$ bem assim como submeter os mesmos a um processo de metacognição, no qual tiveram de reflectir sobre a metodologia usada neste

4 Em nossa concepção, o conceito de conhecimento tácitos pode ser entendido como conhecimentos prévios adquiridos no seu cotidiano. 
processo de ensino e aprendizagem [...] os alunos tomaram consciência de que 0 enfoque dado às suas idéias é importantíssimo para o sucesso educativo (FERREIRA, et al., 2004, p. 157).

Um dos apontamentos enfatizado no final do trabalho pelas pesquisadoras diz respeito à importância do educador saber o nível conceitual dos seus alunos sobre os itens que serão discutidos no conteúdo a ser trabalhado. Podemos ver na leitura do relatório que este fator foi, decerto, a base de toda a pesquisa. Outra questão enfatizada pelas autoras foi a interação dos alunos através de grupos de discussão. Apesar do relatório ser apresentado de forma resumida, constatamos a preocupação do grupo em demonstrar as vantagens de usar tal interação. Outro quesito presente no texto diz respeito ao trabalho de mediação realizado durante a pesquisa, ou seja, as professores foram agentes "provocadoras" dos alunos, fator este imprescindível para a construção do saber.

Buscando fazer uma contextualização dos resultados da pesquisa com a literatura presente nas academias brasileiras sobre 0 assunto, percebemos que vários autores salientam a importância do professor, antes de ministrar um novo assunto, fazer uma avaliação diagnóstica5 (MORETTO, 2003; LUCKESI, 2002). Após esta avaliação, o professor terá subsídios para traçar estratégias que visam contribuir para que o aluno saia do senso comum para 0 conhecimento científico. Também é importante ressaltar que a interação alunoaluno ou aluno-professor, bem como a própria mediação do professor durante o trabalho representa uma ação pedagógica que, segundo Vygotsky, pode apresentar ricos frutos, uma vez que o aluno poderá sair de uma Zona de Desenvolvimento para outra (REG0, 1995; OLIVEIRA, 1995; DUARTE, 2004).

Feito todo o processo de contextualização quanto ao tema escolhido para a pesquisa bem como sua metodologia, a partir de então apresentaremos a sistematização e os resultados do teste piloto realizado. Porém, primeiramente se faz necessário uma prévia discussão teórica sobre referido instrumento de coleta de dados numa pesquisa científica.

5 Aqui se faz necessário lembrar que segundo os autores consultados, toda a avaliação é diagnóstica. Sendo assim, em todo o momento avaliativo o professor terá elementos para direcionar e replanejar suas aulas. Esta idéia contradiz alguns educadores que advogam que a avaliação diagnóstica é feita somente no início do processo. 
Qual seria, em linhas gerais, a utilidade deste procedimento para 0 trabalho? Logo no início destas considerações, é pertinente destacar que vários autores enfatizam a relevância da execução e análise do teste piloto por parte do pesquisador. Em suma, podemos salientar, baseados na literatura, que devido ao dinamismo da pesquisa, a verificação prévia do instrumento de coleta de dados poderá levantar subsídios para possíveis encaminhamentos que poderão mudar pontos importantes no trabalho (LAKATOS; MARCONI, 2001; CHIZZ0T'TI, 1991).

Nesta mesma linha de pensamento, ANDRÉ (1995, p. 28-29) destaca que a constante interação entre objeto e pesquisador, presente na pesquisa qualitativa do tipo etnográfica, "[...] permite que ele responda ativamente às circunstâncias que 0 cercam, modificando técnicas de coleta, se necessário, revendo questões que orientam a pesquisa, localizando novos sujeitos, revendo toda a metodologia ainda durante 0 desenrolar do trabalho". Portanto, o contato preliminar com o objeto de estudo possibilita aparar arestas e, assim, redirecionar os instrumentos de coleta de dados visando atingir o foco preestabelecido.

Diante da importância deste elemento para a pesquisa, antes de realizarmos 0 procedimento, foram verificados alguns quesitos. A primeira questão observada foi em relação as instituições de ensino que seriam selecionadas, uma vez que as duas escolas escolhidas tinham que atender um público com características próximas do eleito para a execução do trabalho final. Sendo assim, além do público, itens tais como: material didático utilizado, tamanho das turmas, questão geográfica - localização da escola no município - foram observados. Outro fator que se levou em consideração foi a necessidade de serem instituições distintas no que tange à manutenção das mesmas, isto é, uma instituição pública e outra particular de ensino.

Após observados todos estes itens acima descritos, foram selecionadas duas instituições de ensino. Em ambas, o teste piloto foi aplicado no último bimestre do ano letivo de 2005 para turmas da 5 a série do Ensino Fundamental. A opção da série se deu devido a necessidade da turma não ter estabelecido contato com o conteúdo: "Sociedade e trabalho na Idade Média" que enfocamos na realização do nosso trabalho. ${ }^{6}$

6 É relevante destacar que devido ao pouco tempo para realização da pesquisa, optamos por aplicar o teste piloto, somente antes do conteúdo. Porém, na parte final do trabalho o instrumento será composto de duas 
Alguns detalhes pertinentes às instituições pesquisadas devem ser expostos antes da análise das resposta em si. A primeira característica a ser levada em consideração diz respeito à diferença quanto ao número de alunos em sala bem como a idade dos mesmos. Ou seja, a sala de aula pertencente à escola pública era constituída por 33 alunos com idades que variavam de 10 a 15 anos, sendo que $82 \%$ dos discentes tinham 11 anos completos. Quanto ao estabelecimento de ensino pertencente à rede privada, 94\% dos 15 alunos tinham, no momento da aplicação do questionário, 11 anos.

Quanto ao primeiro item, número de alunos, apesar de haver o dobro de crianças na escola pública, sabemos que tal sala, tratando de escola pública, está abaixo da média nacional. 0 professor com este número de alunos se tiver apoio pedagógico e recursos didáticos poderá fazer um bom trabalho. Porém, se faz pertinente enfatizar que para a execução de um bom trabalho pedagógico, é necessário a participação de todo o grupo, ou seja, professores, coordenadores e direção.

As duas professoras regentes das referidas instituições eram graduadas em História e ambas tinham especialização. Quanto ao tempo de formação, a da rede particular formara-se em 2003 e a da rede pública graduou-se em 1999. A professora que leciona na escola pública estava substituindo um colega, ou seja, não tinha iniciado com aquela turma 0 ano letivo. Em nossa concepção, a troca de professor prejudica consideravelmente 0 trabalho, uma vez que devido às idiossincrasias, as propostas iniciais acertadas entre a turma e 0 primeiro professor corre o risco de mudar de foco.

Feito as exposições iniciais sobre todo o contexto que permeou a execução do teste piloto, passaremos a analisar as diferentes questões e respostas do instrumento aplicado. Porém, se faz necessário exortar aos leitores que não pretendemos com tais ponderações fazer uma "cartilha" ou "manual de instrução". 0 objetivo é compartilhar nossa experiência com o intuito de provocar reflexões visando arregimentar mais professores-pesquisadores para esta árdua luta que é a formulação de arcabouço epistemológico sobre "Ensinar História".

partes. Ou seja, visando levantar os conhecimentos prévios será aplicado o instrumento de coleta de dados antes do conteúdo. Após o docente ministrar as aulas pertinente ao tema, será realizado novamente 0 mesmo teste. Com os dados em mãos será possivel analisar se houve modificações na construção do conceito sobre trabalho e sociedade na Idade Média. 
0 instrumento em questão foi dividido em duas partes: a primeira visou analisar elementos que poderiam servir de base para a construção do conhecimento referente ao assunto pesquisado, isto é, acesso a internet, livros e filmes; na segunda parte pretendeu verificar o nível de compreensão que os alunos teriam sobre 0 assunto, em outras palavras, qual seria o nível de conhecimento prévio sobre temas pertinentes ao período histórico selecionado como referencial da pesquisa.

Em relação à primeira parte, o questionário foi subdividido em cinco itens. Fazendo um relato das respostas obtidas, constata-se que apesar dos alunos da instituição pública não possuírem computador com acesso a internet na escola, $85 \%$ dos discentes questionados responderam que têm acesso a rede mundial de computador em casa ou em cyber café. Entre os sites visitados, os discentes da instituição pública destacaram que visitam sala de bate-papo, fazem pesquisa escolar, participam de jogos e ouvem música pelo computador, sendo que a opção mais escolhida foi jogos. Portanto, podemos inferir que apesar da referida escola não disponibilizar computadores com acesso à internet, os alunos procuram outros meios de estarem conectados à rede.

Quanto aos alunos da rede particular, seja na escola ou em casa, todos responderam que habitualmente se conectam à internet. A grande vantagem que levam em relação aos outros discentes neste quesito é que, como em seu ambiente de ensino têm acesso à internet, ficam em média 1 hora por semana conectados tendo um professor ao seu lado para orientá-los em suas pesquisas acadêmicas. As preferências de sites que recebem suas visitas não mudam em relação aos seus colegas da escola pública. 0 que muda é a porcentagem em relação ao todo que responderam utilizar o computador para pesquisar conteúdo escolar.

Outra pergunta relativa à primeira parte buscava levantar dados quanto à leitura dos alunos. A grande maioria dos alunos pesquisados nas duas escolas informaram que lêem em média 3 a 5 livros por ano. Três alunos pertencentes à escola pública responderam que não tinham lido nenhum livro ainda naquele ano.

Ainda no instrumento havia uma pergunta referente ao número de filmes a que os alunos assistiam por mês. Somente dois alunos - rede pública - responderam que não tinham o hábito de assistir a filmes. 0 restante do grupo relatou que habitualmente tem acesso a este tipo de entretenimento. 
Houve uma rica associação entre quantidade de filmes assistidos e respostas que se aproximaram do conhecimento histórico científico. Logo adiante teceremos algumas considerações sobre 0 assunto.

A quarta questão, última da primeira fase, se referia à importância do estudo da História. A maioria dos alunos, seja da escola pública ou particular, respondeu que era relevante o estudo histórico. Somente um discente da escola particular respondeu laconicamente que "não, porque é sobre coisas de antes". Tivemos um terceiro grupo de alunos que afirmaram que era importante, porém chata. Dada a importância deste questionamento, serão apresentadas e, no momento posterior, analisadas com mais afinco algumas respostas obtidas.

Começando pela terceiro grupo de alunos acima citado, apontaremos alguns exemplos: o primeiro aluno, que pertence à escola particular, é enfático ao afirmar que sim, porém termina sua justificativa dizendo que não gosta de História; outro da mesma instituição salienta que "mais ou menos é importante, só que como eu não gosto fica difícil considerar importante"; já um aluno da escola pública responde: "mais ou menos porque tem parte boas e ruins. Bom é desenhar e ruim é ler e responder".

Alguns alunos, como já reportamos, acham pertinente os estudos históricos. Citaremos, $\log 0$ a seguir, algumas respostas selecionadas. Um estudante da escola particular mencionou que a disciplina em questão é importante para nos localizarmos quando estivermos em algum local histórico; outro, da mesma escola, salientou que os estudos são importantes para conhecer o que os avós sabiam; outro se referiu às tradições, ou seja, "sim, pois aprendemos os costumes e tradições"; e por último, um aluno também da mesma escola relatou que "sim, é a da nossa sociedade que estamos falando".

Assim como no estabelecimento privado de ensino, tivemos também diferentes respostas dos alunos pertencentes à rede pública. A primeira a ser destacada enfatiza que é importante pois "você estuda sobre arte passadas e discute dúvidas"; outro discente foi mais incisivo na sua resposta: "sim, pois podemos saber o que aconteceu no passado e como chegamos aos dias atuais"; seu colega de classe considera que o estudo da História é um valioso instrumento de predição, isto é, para ele "saber sobre a vida dos antigos é bom para sabermos coisas do futuro". Tivemos um aluno

\footnotetext{
7 Nos fragmentos de relatos transcritos para o texto, foram mantidas as grafias originais dos alunos.
} 
que foi enfático e direto em sua afirmação: "Sim, considero importante porque quem sabe no futuro podemos ser professor de história".

Fazendo uma leitura sobre as respostas obtidas, constatamos que boa parte dos alunos vêem utilidade para o ensino de História. Para este grupo a História tem significado pois permite conhecer relatos sobre lugares, histórias de familiares, ou seja, algo pertinente ao seu mundo. Esses apontamentos mostram uma relação da utilidade do conhecimento com o contexto vivido pelo aluno.

Outro ponto a ser destacado nas respostas diz respeito à visão pragmática que muitos indivíduos têm da utilidade do conhecimento. Para exemplificar, retomaremos a resposta de um aluno sobre a questão da utilidade da História. Segundo ele, "[...] é importante porque quem sabe no futuro podemos ser professor de história". Apesar de pontual e vir de uma criança de onze anos de idade, reflete a uma concepção na qual o conhecimento tem que ser voltado para as questões técnicas, ou seja, relacionado diretamente a uma profissionalização e conseqüente utilização para o mercado de trabalho.

Essa taylorização do conhecimento fez com que as ciências humanas perdessem seu papel na formação do homem. Porém, para quem defende a inutilidade dos conhecimentos históricos, não é redundante retomar as palavras de um prisioneiro nazista na Segunda Guerra Mundial . Para ele "[...] a incompreensão do presente nasce fatalmente da ignorância do passado [ignorância esta que poderia ter contribuído para a ascensão Nazista]"( BLOCH, 2001, p. 65)

Na segunda parte do instrumento, buscou-se verificar de forma pontual o conhecimento dos alunos no que tange ao tema: "Sociedade e trabalho na Idade Média". Podemos salientar que, como não tinham contado prévio com o conteúdo, a maioria dos alunos presentes na pesquisa tiveram dificuldades em responder às questões propostas.

É importante ponderar e compartilhar com o leitor a seguinte questão: alunos que tiveram acesso a mais filmes e livros mostraram conhecer detalhes importantes sobre Idade Média. Expressando de outra maneira, possuíam conhecimentos históricos aproximados ou científicos em detrimento à grande maioria que detinha um conhecimento de senso comum ou subjetivo.

Para exemplificar esta relação, citaremos o caso de um aluno da escola particular. Este, quanto questionado sobre o que conhecia sobre Idade Média, conseguiu fazer uma diferenciação entre escravos e servos. Tal aluno assinalou 
que assiste em média a dez ou mais filmes por mês e lê onze ou mais livros por ano. Quando o assunto é internet, sua única opção foi a pesquisa escolar.

Dois alunos da escola pública chamaram nossa atenção. 0 primeiro, ao ser questionado sobre o mesmo tema do aluno já citado, respondeu: "Eu vi uma vez um desenho que falava que a Idade Média era um tempo em que tinha reis, princesas, e muitos cavaleiros com armaduras e eles usavam grandes lanças para combater outras pessoas". Em seu desenho, que era a última atividade proposta, ele explicou que o mesmo representava "um rei com medo do cavaleiro com o cavalo e um outro cavaleiro protegendo o rei". Seu colega respondeu que nesta época havia "cidades muradas, castelos, princesas, reis e rainhas [...]". 0 que podemos verificar é que esses dois alunos acima mencionados assistiram em média a mais filmes e leram mais livros que seus colegas de sala.

As afirmaç̧ões acima podem parecer óbvias, ou seja, quem tem mais acesso à informação conseqüentemente poderá deter mais informação. Se isto é um paradigma que todos conhecemos, por que os professores de história não estabelecem estratégias para tirar proveito da mesma? Sem entrar no mérito do calendário escolar ou na rotina estressante dos três turnos diários, a utilização de recursos audiovisuais são instrumentos didáticos muito úteis.

Novamente, não querendo ditar regras "pedagógicas" ou ainda "receitas" que levariam ao sucesso do professor, acreditamos que algumas provocações se tornam úteis dentro do contexto. Por exemplo, alguns cuidados devem ser tomados ao optarmos por trabalhar com vídeos em sala. 0 primeiro, é uma rica preparação do material. Esta fase envolve desde da seleção do filme, bem como exige que o professor tenha tempo disponível para assisti-lo antes de exibir 0 material para 0 aluno.

Se faz necessário enfatizar também que tal recurso a ser utilizado demanda uma preparação da sala para a "sessão de cinema". Isto é, os alunos deverão ter elementos para poder identificar no material as idéias, sejam elas diretas ou ainda, se possível, mensagens subliminares (ROCHA, 1993; RANZI, 1998). Como última provocação, devemos 'banir" do meio acadêmico a idéia que ainda persiste de que o filme é uma estratégia rápida e fácil para preencher 0 calendário escolar. Segundo MEIRELLES (2004), o uso de filmes em sala de aula não é simplesmente diversão, mas quando bem trabalhado se transforma 
num rico material de apoio pedagógico que contribui, de forma decisiva, no processo de ensino-aprendizagem de História.

Como última ponderação em relação aos dados obtidos no instrumento aplicado, voltaremos à questão dos conceitos prévios. Grande maioria dos alunos confundiu servos com escravos e conseqüentemente nobre com senhor de engenho. Este fato, que a princípio seria um problema, poderá, se bem trabalhado, ser um aliado do professor. Novamente gostaria de enfatizar a necessidade de uma avaliação diagnóstica, pois, detentor dessas informações, poderá utilizá-las a seu favor no momento de elaborar seu planejamento.

Portanto, o professor que estiver atento a este fato poderá contribuir de forma decisiva para que o aluno, dentro de sua especificidade, venha a ser desafiado de forma apropriada. Parafraseando BZUNECK (2002), o grau da tarefa deve ser apropriado ao nível de desenvolvimento do aluno, isto é, muito fácil causa tédio; muito difícil causa ansiedade e fracasso.

Durante a exposição dos resultados obtidos no trabalho pode-se constatar que alguns dados a priori questionaram a rápida pesquisa que realizamos durante o estágio obrigatório, já citado no texto. Apesar desta constatação, em nossa concepção, não podemos afirmar peremptoriamente que estes alunos sejam diferentes dos participantes da primeira pesquisa. Essa questão será melhor estudada com as análises dos dados coligidos na parte final da pesquisa.

Finalizando nossa conversa, essa possível contradição entre dados obtidos em diferentes pesquisas fez com que acrescentássemos um novo instrumento de coleta de dados, a saber: entrevista com alguns discentes. Esta mudança só foi possível graças ao teste piloto bem como o modelo de pesquisa escolhido, 0 qual permite durante todo o trajeto do trabalho a inserção de novos instrumentos de coleta de dados. Diante desta constatação, confirmamos na prática a ứilidade deste valioso instrumento - teste piloto - em uma pesquisa acadêmica. 


\section{Referências}

ANDRÉ, Marli Eliza Dalmazo Afonso de. Etonografia da prática escolar. 11.ed. Campinas: Papirus, 1995.

BARROS, José D’Assunção. O campo da História: especialistas e abordagens. Petrópolis: Vozes, 2004.

BLOCH, Marc Leopold Benjamin. Apologia da hitória ou, ofício de historiador. Rio de Janeiro: Jorge Zahar Ed., 2001.

BRANDÃO, Carlos Rodrigues. O que é educação. São Paulo: Brasiliense, 1989.

BURKE, Peter. A Escola dos Annales (1929 - 1989): a revolução francesa da historiografia. São Paulo: UNESP, 1997.

. História e teoria social. São Paulo: Editora da UNESP, 2002.

BZUNECK, José Aloyseo. A motivação do aluno orientado a metas de realização. In: BORUCHOVITCH, Evely; BZUNECK, José Aloyseo. A motivação do aluno: contribuição da psicologia contemporânea. 2. ed. Petrópolis: Vozes, 2002. p. 58-77.

CABRINI, Conceição. Ensino de bistória: revisão urgente. São Paulo: EDUC, 2000.

CARDOSO, Ciro Flamarion Santana. Uma introdução à História. 4. ed. São Paulo: Brasiliense, 1984 .

CHIZZOTTI, Antonio. Pesquisas em ciências bumanas e sociais. São Paulo: Cortez, 1991.

COLLINGW00D, Roger George. A ideia de história. Lisboa: Presença, [196-?].

DOSSE, François. A História em migalhas: dos "Annales" à "Nova História". São Paulo: Ensaio; Campinas: Unicamp, 1998.

DUARTE, Newton. Vigotski e o "aprender a aprender": crítica às apropriações neoliberais e pós-modernas da teoria vigotskiana.3. ed. Campinas: Autores Associados, 2004.

FERREIRA, Arminda et al. 0 conceito de Renascimento: uma experiência educativa com alunos de $8^{\circ}$ ano. In: BARCA, Isabel. Para uma educação bistórica de qualidade. Braga: Universidade do Minho, 2004. p. 147- 166.

GARDINER, Patrick. Collingwood. In: Teorias da bistória . Lisboa : Funcação Calouste Gulbenkian, 1984. p. $302-319$. 
HOBSBAWN, Eric John. Sobre História. São Paulo: Cia das Letras, 1998.

HUGHES-WARRINGTON, Marnie. 50 grandes pensadores da bistória. São Paulo: Contexto, 2002.

LAKATOS, Eva Maria; MARCONI, Marina de Andrade. Fundamentos de metodologia científica. 4. ed. São Paulo: Atlas, 2001.

LE GOFF, Jacques; NORA, Pierre. História: novos problemas. 2. ed. Trad. Theo Santiago. Rio de Janeiro: Francisco Alves, 1979. . História: novas abordagens. 3.ed. Rio de Janeiro: Francisco Alves, 1988a. História: novos objetos. . Rio de Janeiro: Francisco Alves, 1988b.

LUCKESI, Cipriano Carlos. Avaliação da aprendizagem escolar. 12. ed. São Paulo: Editora Cortez, 2002.

MEIRELLES, Willian Reis. 0 cinema na história: o uso do filme como recurso didático no ensino de história. História \& Ensino, Londrina, v.10, p. 77-88, out. 2004.

MORETTO , Vasco Pedro. Prova: um momento privilegiado de estudos, não um acerto de contas. 3 ed. Rio de Janeiro: DP\&A, 2003.

OLIVEIRA, Marta Kohl de. Vygotsky: aprendizado e desenvolvimento um processo sóciohistórico. 2. ed. São Paulo: Scipione, 1995.

PERRENOUD, Philippe. Saber Refletir sobre a Própria Prática: Objetivo Central da Formação dos Professores. In. A prática reflexiva no ofício de professor. Profissionalização e razão pedagógica. Porto Alegre, ARTMED, 2002.

PINSKY, Jaime; PINSKY, Carla Bassanezi. Por uma história prazerosa e conseqüente. In: KARNAL, Leandro (Org.). História na sala de aula: conceitos, práticas e propostas. Sao Paulo: Contexto, 2003. p. 17-36.

RANZI, Serlei Maria Fischer. Cinema e aprendizagem em história. História \& Ensino, Londrina, v.4, p. 25-33, out. 1998

REALE, Giovanne; ANTISERI, Dario. História da filosofia. Da antiguidade à Idade Média. São Paulo: Paulus, 1991.

REGO, Tereza Cristina. Vygotsky: uma perspectiva histórico-cultural da educação. 2. ed. Petrópolis: Vozes, 1995.

REIS, José Carlos As identidades do Brasil: de Varnhagem a FHC. $5^{\mathrm{a}}$ ed. Rio de Janeiro:Editora da FGV, 2002. 
. A História: entre a filosofia e a ciência. 3.ed. Belo Horizonte: Autêntica, 2004.

REMOND, Réné (org.). Por uma bistória politica. São Paulo: FGV, 1998.

RIBEIRO JR, João. O que é positivismo. São Paulo: Brasiliense, 1996.

ROCHA, Antonio Penalves. 0 filme: um recurso didático no ensino de história? In: FRANCO, Maria da Silva et al. Coletânea lições com o cinema. São Paulo: FDE, 1993. p.69-86

ROCHA, Ubiratan. Reconstruindo a história a partir do imaginário do aluno. In: NIKITIUK, Sonia M. Leite (org.). Repensando o ensino de bistória. São Paulo: Cortez, 1999.

SAVATER, Fernando. O valor de Educar. São Paulo: Martins Fontes, 1998.

TERRA, Ricardo Ribeiro (org.) . Idéia de uma bistória universal de um ponto de vista cosmopolita, de Immanuel Kant. São Paulo: Brasiliense, 1986.

TÉTART, Philippe. Pequena bistória dos bistoriadores. Bauru: EDUSC, 2000.

TRIVIÑOS, Augusto Nibaldo Silva. Introdução à pesquisa em ciências sociais: a pesquisa qualitativa em educação. São Paulo: Atlas, 1987.

VILLALTA, Luis Carlos. Dilemas da relação teoria e prática na formação do professor de história: alternativas em perspectiva. Revista Brasileira de História, São Paulo, v.13,n.25/ 26, p.223-240, set. 92/ago.93.

\section{Historiography and education of History: some reflections on Basic Ensino.}

\section{Abstract}

This article has as objective to present an analysis of the results from the pilot test of a research accomplished the Education master's degree program of the Universidade Estadual de Londrina that intends to recognize the influence of the slopes historiographies in the History teachers'day by day that acts in the Fundamental Teaching. In the above-mentioned stage of the research we looked 
for testing the validity of the data. So that, we worked with two groups of fifth grades'students, one from a public school, and the other from a private school. These students answered a questionnaire which was composed of two parts. In the first, we prioritized to collect data on the access of the students in the internet, films and the literature. In the final stage, five questions were applied in order to collect information regarding the previous knowledge or tacit nouns concerning the society and the work in the Medium Age.

Key wrords: Teaching of History, Methodology of Teaching, Historiography. 